\title{
ARTíCULOS
}

\section{HISTORIADORAS: UNA PROSOPOGRAFÍA DE CUATRO DE LAS PIONERAS DE LA INVESTIGACIÓN HISTÓRICA EN ESPAÑA}

\author{
Women Historians: a prosopography of four Spanish pioneers of research in \\ History
}

\author{
Alejandro Camino Rodríguez \\ Universidad Autónoma de Madrid \\ alejandro.camino@uam.es
}

Recibido: 02/04/2017 - Aceptado: 08/08/2017

Cómo citar este artículo/Citation:

Alejandro CAMINO RODRÍGUEZ (2018), "Historiadoras: una prosopografía de cuatro de las pioneras de la investigación histórica en España”, Hispania Nova, 16, págs. 197-226, DOI: https://doi.org//0.203/8/hn.2018.4036
Copyright: () HISPANIA NOVA es una revista debidamente registrada, con ISSN II38-73I9 y Depósito Legal M 9472-1998. Los textos publicados en esta revista están -si no se indica lo contrario- bajo una licencia Reconocimiento-Sin obras derivadas 3.0 España de Creative Commons. Puede copiarlos, distribuirlos y comunicarlos públicamente siempre que cite su autor y la revista y la institución que los publica y no haga con ellos obras derivadas. La licencia completa se puede consultar en: http://creativecommons.org/licenses/by-nd/3.0/es/deed.es
Resumen: María del Pilar Corrales, Matilde Moliner, Amada López de Meneses y María Luisa González fueron cuatro de las pioneras en la investigación histórica en España. Estudiar su trabajo y sus vidas proporciona un marco privilegiado para analizar los retos y problemas a los que tuvieron que enfrentarse las mujeres pertenecientes a las primeras generaciones de investigadoras en España, así como para determinar y evaluar su perfil social y cultural. Esta prosopografía estudia la trayectoria profesional y personal de estas mujeres, con los objetivos principales de, por un lado, analizar cómo estas investigadoras negociaron con los diferentes modelos de género oficiales $y / o$ hegemónicos de la época en la que transcurrieron sus vidas $y$, por otro lado, evaluar si desarrollaron una trayectoria investigadora y profesional prolífica $y$ exitosa.

Palabras clave: investigadoras, historiadoras, España, relaciones de género, prosopografía.

\begin{abstract}
María del Pilar Corrales, Matilde Moliner, Amada López de Meneses and María Luisa González were four of the first female historians in Spain. Studying their work and lives provides a privileged framework for analysis of the challenges and problems faced by women belonging to the first generations of researchers in Spain. Moreover, it enables us to assess their social and cultural profile. This prosopography studies their professional and personal paths, having two main objectives. Firstly, it analyses how these Spanish researchers negotiated with the different official and/or hegemonic gender models. Secondly, it attempts at assessing whether these women developed successful and prolific professional careers.
\end{abstract}

Keywords: female researchers, women historians, Spain, gender relations, prosopography. 


\section{Introducción, metodología, hipótesis y objetivos}

Esta es una prosopografía de cuatro historiadoras: María del Pilar Corrales (y) Gallego, Matilde Moliner Ruiz, Amada López (de) Meneses y María Luisa González (y) Rodríguez. Las cuatro se licenciaron en Filosofía y Letras en la década de 1920 y pertenecieron al selecto grupo de investigadoras que fueron pensionadas (o equiparadas a pensión) por la Junta para la Ampliación de Estudios e Investigaciones Científicas (JAE). Si bien no forman parte del grupo de las primeras mujeres licenciadas, destacan porque buscaron utilizar a lo largo de toda su vida el título académico para desarrollar una trayectoria profesional asalariada y una actividad investigadora en el ámbito de la historia. Hasta la actualidad, estas investigadoras apenas han sido objetos/sujetos de estudios historiográficos ${ }^{1}$, a diferencia de otras historiadoras más destacadas como Teresa Andrés Zamora o Mercedes Gaibrois.

Para realizar este tipo de investigación considero que la metodología más útil es la prosopografía, teniendo en cuenta que el estudio se centra en unas décadas en las que el número de investigadoras todavía es lo suficientemente reducido como para poder trabajar sobre cada una individualmente. La tendencia biográfica a la que se adscribe mi trabajo es aquella que ha venido denominándose historia biográfica, término acuñado por Sabina Loriga ${ }^{2}$. Esta perspectiva se guía, aunque de forma sensible y adaptada, por los problemas históricos/historiográficos generales porque se considera que es una aproximación al pasado que debe asumir como propios todos los problemas que se plantea la historia como disciplina. Por este motivo, el presente estudio prosopográfico trata de agudizar la tensión analítica entre lo colectivo y lo individual, estudiando a estas licenciadas no de forma aislada, sino en relación con los

\footnotetext{
${ }^{1}$ La excepción es Matilde: Josefa OTERO OCHAÍTA, "Matilde Moliner. El timbre ha sonado inesperadamente", Participación educativa, 1 (2011), pp. 115-126; Inmaculada de la FUENTE, "El reto de llamarse Matilde Moliner", Clarín: Revista de nueva literatura, 103 (2013), pp. 58-62.

2 Isabel BURDIEL y Roy FOSTER, “Introducción”, Isabel BURDIEL y Roy FOSTER (eds.), La historia biográfica en Europa. Nuevas perspectivas, Zaragoza, Institución Fernando el Católico. Excma. Diputación de Zaragoza, 2015, pp. 9-15.
} 
avances y retrocesos (legales, prácticos y discursivos) que experimentaron las mujeres españolas durante la primera mitad del siglo XX.

El gran beneficio de realizar biografías o prosopografías desde la perspectiva de género, es que la biografía y el género se auxilian historiográficamente para descender desde las normativas oficiales y/o hegemónicas a las profundidades de lo vivido. Esto es especialmente útil porque permite analizar a las mujeres no como víctimas pasivas del orden desigual, sino como sujetos activos capaces de negociar las normativas oficiales y/o hegemónicas de género. Esto se debe a que aunque los modelos hegemónicos y oficiales de género son frecuentemente presentados como marcos fijos y determinantes, sólo son condicionantes, porque pese a sus imposiciones también permiten márgenes de acción, expresión y elección, los cuales posibilitan que las pautas colectivas puedan adaptarse 0 transformarse ${ }^{3}$. Además, las prosopografías suponen un enfoque inmejorable para profundizar en las diferencias y en las semejanzas que tuvieron los recorridos profesionales y vitales de unas historiadoras que tenían el mismo nivel de estudios y que procedían de contextos sociales similares.

Los objetivos de la prosopografía fueron principalmente dos: en primer lugar, valorar si estas mujeres transgredieron los diferentes modelos de género oficiales y/o hegemónicos bajo los que transcurrió su vida. En segundo lugar, analizar si pudieron alcanzar las expectativas laborales, académicas y personales que tenían cuando terminaron la licenciatura y, en el caso de que no las consiguiesen, cuáles fueron los motivos, centrándome especialmente en examinar la relación entre el ámbito familiar y afectivo de estas mujeres y su vida profesional y académica. La pertinencia de estos análisis radica en que sus conclusiones pueden ser de gran utilidad para comparar las vivencias y trabas adicionales que, por el hecho de ser mujer, sufrieron estas historiadoras pertenecientes a la primera generación de investigadoras en España (las

\footnotetext{
${ }^{3}$ Mónica BOLUFER, "Multitudes del yo: biografía e historia de las mujeres", Ayer, 93 (2014), p. 112; María SIERRA, "Las fuentes del yo íntimo: biografía y virilidades románticas", Isabel BURDIEL y Roy FOSTER (eds.), La historia biográfica en Europa. Nuevas perspectivas, Zaragoza, Institución Fernando el Católico. Excma. Diputación de Zaragoza, 2015, p. 243; Kathleen CANNING, Gender History in Practice. Historical Perspectives on Bodies, Class and Citizenship, Ithaca-Londres, Cornell University Press, 2006. Tampoco hay que perder de vista que la prosopografía es una herramienta útil para investigar las comunidades profesionales.
} 
investigadoras anteriores son demasiado excepcionales) con respecto a las experimentadas por las generaciones posteriores ${ }^{4}$.

Ante el poco tratamiento de estas personas por parte de la historiografía, el trabajo fundamentalmente se ha construido a partir del uso de fuentes primarias. Sin embargo, igual que el resto de investigadores/as que abordan temas relacionados con las mujeres universitarias en España durante finales del siglo XIX y la primera mitad del $X X$, me he enfrentado a las dificultades que entraña la localización de los documentos que permiten su estudio. A esto, además, hay que sumar el problema de que frecuentemente las fuentes disponibles no proporcionan información para poder responder con la profundidad necesaria/deseada preguntas históricas de carácter general ${ }^{5}$.

\section{Prosopografía de cuatro mujeres licenciadas en Filosofía y Letras}

\subsection{Contexto histórico}

El año 1910 es una fecha importante para entender las realidades académicas femeninas porque marcó, legal y simbólicamente, un antes y un después para las mujeres españolas, especialmente para quienes por su situación socioeconómica podían permitirse acceder a la universidad. La Real Orden de 8 de marzo estipuló la libertad de acceso de las mujeres a las aulas universitarias en igualdad de condiciones formales que los hombres. Además, la Real Orden de 2 de septiembre otorgó validez profesional al título universitario de las mujeres para los empleos que dependían del Ministerio de Instrucción Pública y Bellas Artes. De esta manera, que una mujer

\footnotetext{
4 Darina MARTYKÁNOVÁ y Alejandro CAMINO RODRÍGUEZ, "Las carreras académicas de las investigadoras en España: una contextualización europea", Más Allá de las Cifras, Santander, 7 de marzo de 2017.

${ }^{5}$ Sobre los problemas de localización de las fuentes que permiten el estudio de las universitarias españolas: Josefina CUESTA, Consuelo FLECHA, María Jesús MATILLA, M ${ }^{a}$ Luz de PRADO y Sofía RODRÍGUEZ, "Dificultades de las fuentes para el estudio de la historia de las mujeres en la universidad española", Pilar FOLGUERA et al. (eds.), Pensar con la Historia desde el siglo XXI. XII Congreso de la Asociación de Historia Contemporánea, Madrid, UAM ediciones, 2015, pp. 945-963. Para una revisión historiográfica de los estudios de las mujeres universitarias en España: Pilar BALLARÍN DOMINGO, "Entre ocupar y habitar. Una revisión historiográfica sobre Mujeres y Universidad en España", Arenal, 17 (2010), pp. 223-254.
} 
obtuviese se licenciase dejó de tener sólo una connotación cultural, ya que desde entonces las licenciadas podían encontrar salidas laborales habilitadas por su titulación, al poder presentarse a los concursos públicos destinados a nutrir de profesionales al Cuerpo Facultativo de Archiveros, Bibliotecarios y Arqueólogos (CFABA), al profesorado de segunda enseñanza y al resto de instituciones culturales y cientificas dependientes de ese Ministerio ${ }^{6}$.

Este hecho fue uno de los elementos fundamentales que impulsó que las españolas estudiasen cada vez en mayor medida Filosofía y Letras, ya que las mujeres no quisieron desaprovechar la oportunidad que les ofrecieron las Reales Ordenes de 1910. Por este motivo, la licenciatura de Filosofía y Letras se convirtió, junto a las de Medicina, Farmacia y Ciencias, en una de las opciones mayoritarias por las que optaron las mujeres que pudieron acceder a las universidades españolas. Estas tendencias en España se deben a que eran las licenciaturas que, por diversas razones, les otorgaban mayores posibilidades de integrarse en el mundo profesional, ya que estaba mejor aceptado socialmente que se dedicasen a trabajos de estas ramas al considerarse que se adaptaban mejor que el resto a las normas y expectativas de género hegemónicas ${ }^{7}$.

De todas formas, pese a que en 1910 se eliminasen muchos obstáculos para las mujeres en la normativa legal, siguieron existiendo fuertes resistencias, formales e informales, a la educación superior de las mujeres. Las universitarias e investigadoras españolas fueron discriminadas, explícita o implícitamente, debido a que las mentalidades son más difíciles de modificar que las leyes porque adolecen de inercias. Dentro de esta mentalidad general se entendía que era poco útil para las mujeres cursar estudios universitarios debido a que no eran necesarios para ninguna de las funciones que les asignaban socialmente como adecuadas, en la casa y en la familia

\footnotetext{
${ }^{6}$ Gaceta de Madrid, 9 de marzo de 1910, pp. 497-498; Gaceta de Madrid, 4 de septiembre 1910, pp. 731-732; Carolina RODRÍGUEZ LÓPEZ, "Experiencias universitarias en torno a 1910. En el centenario del acceso de la mujer a los estudios universitarios", CEE Participación Educativa, 15 (2010), pp. 209219.

${ }^{7}$ La consideración general de que una determinada profesión se adapta mejor a las cualidades atribuidas a los hombres o a las mujeres es variable temporal y espacialmente, puesto que es una idea construida socialmente que normalmente sirve, además, para excluir implícitamente a las mujeres de las profesiones de prestigio: Darina MARTYKÁNOVÁ, "La profession, la masculinité et le travail. La représentation sociale des ingénieurs en Espagne pendant la deuxième moitié du XIXe siècle", Antoine DEROUET, Simon PAYE, Christel FRAPIER (eds.), La production de l'ingénieur. Contributions à l'histoire sociale d'une catégorie professionnelle, París, Garnier, 2017 (en prensa).
} 
(incluso en el mundo laboral). Sin embargo se admitía, e incluso se revindicaba en ciertos ámbitos sociales, alguna forma de educación femenina superior, sobre todo para poder complementar mejor al marido en el matrimonio y lucir con cultura en la sociedad, reforzando así el estatus del marido en el ámbito público ${ }^{8}$.

En consecuencia, el que las cuatro biografiadas estudiaran en la universidad y realizaran investigaciones históricas fue una excepción durante las primeras décadas del siglo XX. En términos generales, el acceso a la formación intelectual de alto nivel seguía estando reservado para una minoría, al estar restringido en términos sociales a las clases acomodadas y, dentro de ellas, sobre todo a los varones. Las universitarias en España representaban un ínfimo porcentaje de la población femenina total, pese a que desde 1910 creciesen en número paulatinamente implicando el comienzo de la pérdida de la excepcionalidad (y facilitando que se empezase a considerar como algo prestigioso y moderno). En la década de 1920, que es cuando estas mujeres realizaron los estudios superiores, el porcentaje de universitarias creció desde el 3.9\% al 6.3\%, mientras que la cifra en números absolutos ascendió de 345 (en el curso 1919-1920) a 1681 (en 1927-1928) ${ }^{9}$.

Respecto a la JAE quiero resaltar que fue una de las instituciones más importantes para el desarrollo del capital humano en España durante el primer tercio del siglo XX. La institución, que tenía como uno de sus objetivos principales el modernizar la ciencia española en todas sus vertientes, concedía normalmente las pensiones por la calidad de los proyectos que les presentaban. La escasez de becadas por la JAE, dentro del ya reducido número de pensionados, fue consecuencia de las características socioculturales del primer tercio del siglo XX en España, ya que para pedir la beca individual necesitaban poseer condiciones académicas destacadas, conocer al menos un segundo idioma y, en el caso de las mujeres, contar con la aprobación, en su círculo de sociabilidad cercano, de que pasasen un largo periodo en

\footnotetext{
${ }^{8}$ Jean-Louis GUEREÑA, "Mujeres universitarias en los siglos XIX y XX. Apuntes historiográficos sobre el caso español con un breve enfoque de la situación francesa", Josefina CUESTA, María Luz DE PRADO y Francisco J. RODRÍGUEZ (dirs.), ¿Mujeres sabias? Mujeres universitarias en España y América Latina, Pulim, 2015, p. 27.

${ }^{9}$ También las tasas de analfabetismo eran muy elevadas porque afectaban al $52 \%$ de las mujeres y al $36 \%$ de los varones. Mercedes VILANOVA y Xavier MORENO, Atlas de la evolución del analfabetismo en España de 1887 a 1981, Ministerio de Educación Cultura y Deporte, 1992, pp. 276-277; Carolina RODRÍGUEZ LÓPEZ, "Experiencias universitarias en torno a 1910. En el centenario del acceso de la mujer a los estudios universitarios", CEE Participación Educativa, 15 (2010), pp. 209-219.
} 
el extranjero sin acompañantes. Estos requisitos no los cumplía el grueso de españoles, como prueba el escaso número de solicitudes presentadas a la sección de Historia y Geografía en los años en los que les fue concedida la pensión a estas historiadoras (cuadro 1) y que la JAE sólo concediese 120 pensiones o equiparaciones a pensión para estudiar Historia (11 de ellas adjudicadas a mujeres) ${ }^{10}$. En consecuencia, las cuatro licenciadas estudiadas pertenecieron al reducido grupo de españolas que fueron pensionadas por esta institución, lo cual es algo muy destacable teniendo en cuenta que muchas mujeres destacadas vieron denegadas sus solicitudes, como fue el caso, entre otras, de Margarita Nelken o María de Echarri.

Cuadro 1. Solicitudes de pensión presentadas a la JAE en la sección de Historia y Geografía en los años en los que las pensiones o equiparaciones a pensión les fueron concedidas.

\begin{tabular}{|l|c|c|c|}
\hline Pensionada & Año & Destino & Solicitudes registradas \\
\hline María del Pilar Corrales Gallego & 1925 & Francia & 20 \\
\hline María Luisa González & 1931 & Francia & 16 \\
\hline Matilde Moliner & 1932 & Francia e Inglaterra & 11 \\
\hline Amada López de Meneses & 1932 & Francia & 11 \\
\hline
\end{tabular}

Elaboración propia a partir de los datos ofrecidos por: Teresa MARIN ECED, Los pensionados en educación por la J. A. E. y su influencia en la pedagogía española, Madrid, UCM, 1988, p. 289.

En cuanto a la situación de la profesión de historiador en España durante el primer tercio del siglo XX, hay que destacar que entre 1900 y 1936 se produjo una ampliación de puestos de profesorado en las universidades españolas, de los cuales un número considerable fueron ocupados por historiadores que habían sido pensionados por la JAE. Sin embargo, la carrera profesional estaba diseñada de una manera en la que los catedráticos controlaban la disciplina y el sistema de cooptación y de contratación de ayudantes y adjuntos. Entonces, como los nombramientos no estaban regidos necesariamente por criterios impersonales, el sexo del candidato influía a la hora de obtener un puesto, encontrándose las mujeres con mayores dificultades que los varones para acceder a los puestos docentes universitarios, porque frecuentemente los catedráticos no las consideraban suficientemente preparadas. Además, durante el primer tercio del siglo las mujeres que consiguieron dedicarse

10 Pueden consultarse en: http://archivojae.edaddeplata.org/jae app/; Sobre la JAE, por ejemplo: Josefina GÓMEZ MENDOZA, La Junta para Ampliación de Estudios e Investigaciones Científicas y los académicos de la historia, Real Academia de la Historia, 2008; Miguel Ángel PUIG-SAMPER (ed.), Tiempos de investigación. JAE-CSIC. Cien años de ciencia en España, CSIC, 2007; José María LÓPEZ SÁNCHEZ, Heterodoxos españoles. El Centro de Estudios Históricos, 1910-1936, Madrid, Marcial Pons, 2006. 
profesionalmente a la investigación o a la docencia universitaria no tuvieron estabilidad profesional; de hecho, en el caso de la universidad ninguna consiguió tener una plaza en propiedad ${ }^{11}$.

Como la inestabilidad tiene connotaciones negativas para la vida profesional y personal, la práctica totalidad de investigadoras de antes de la guerra civil se dedicaron poco tiempo a estas actividades, ya que desistían "voluntariamente" y optaban por intentar conseguir una plaza por oposición en la enseñanza secundaria o en archivos, bibliotecas o museos, que eran opciones laborales con criterios de selección menos arbitrarios y que ofrecían la garantía de poder consolidarse profesionalmente de forma más rápida. El que las investigadoras optasen mayoritariamente por estos caminos se debe a que estaban insertas en un contexto en el que, como se discriminaba explícita e implícitamente a las mujeres en el mundo académico, terminaban convenciéndose de que ese ámbito, que requería una dedicación plena, no podía ser el eje central de sus vidas porque eso implicaba desatender otras labores que las familias y la sociedad esperaban que cumplieran ${ }^{12}$.

Sin embargo, la guerra civil quebró todos estos procesos. La represión, las depuraciones y el exilio que sufrieron importantes historiadores, sumado a la

\footnotetext{
11 Para la evolución durante el siglo $X X$ de la situación de los historiadores y de la profesión de historiador: Ignacio PEIRÓ, Historiadores en España. Historia de la Historia y memoria de la profesión, Zaragoza, Prensas de la Universidad de Zaragoza, 2013, pp. 19-84; Mary NASH, "Mujeres, género y las fronteras abiertas de la historia: una cartografía intelectual", Jaume AURELL, La historia de España en primera persona. Autobiografías de historiadores hispanistas, Barcelona, Base, 2012, pp. 187-211; André BURGUIĖRE y Bernard VINCENT (dirs.), Un siécle d'historiennes, París, Edition des femmes, 2014. Aunque hay todavía una carencia de trabajos que aborden específicamente la situación de las historiadoras españolas.

${ }^{12}$ Hubo varias trayectorias modelo para las investigadoras y/o profesoras universitarias en Historia durante el primer tercio del siglo XX. Por sólo mencionar los casos de las más destacadas: en primer lugar hubo historiadoras, como Luisa Cuesta, Carmen Gómez o Francisca Pierna, que buscaron pronto conseguir plaza como profesoras de segunda enseñanza o en el CFABA. En segundo lugar se encuentra la trayectoria de mujeres, como Concepción Álvarez o Julia de Francisco Iglesias, a las que la dictadura les privó de seguir su trayectoria como docentes universitarias, aunque pudieron recolocarse posteriormente en las enseñanzas medias o en el CFABA. En tercer lugar hubo mujeres que, como Encarnación Cabré, optaron por tener hijos y centrarse en sus cuidados. En cuarto lugar está la trayectoria de aquellas, como Olimpia Arozena, María Pura o Mercedes Gaibrois, que durante el franquismo (por no considerárselas opuestas al régimen) pudieron mantener sus puestos en la universidad, cuando los tenían, y seguir con su labor investigadora. Por último, también muchas historiadoras, como María Muedra, María Ugarte o Teresa Andrés Zamora, tuvieron que exiliarse debido a la dictadura. Para más información sobre estas mujeres: Consuelo FLECHA, "Profesoras en la Universidad. El tránsito de las pioneras en España", Arenal, 17 (2010), pp. 255-297 y Consuelo FLECHA, "Profesoras de Historia Medieval: mirando a los orígenes", Pilar DÍAZ, Gloria FRANCO y María Jesús FUENTE (eds.), Servicio de Publicaciones Universidad de Huelva, 2012, pp. 105-116.
} 
reconstrucción de la profesión histórica en los primeros años del franquismo, desencadenaron unos momentos cruciales que se han denominado como la "hora cero" de la historiografía española (aunque hubo ciertas continuidades con el periodo anterior $)^{13}$. Todo esto afectó, en mayor o menor medida, el devenir de las trayectorias profesionales y personales de las historiadoras estudiadas, porque tuvo que pasar el tiempo para que las mujeres volviesen a superar barreras y obstáculos ya sobrepasados antes de 1936. Aunque algunas de las académicas que no sufrieron la represión en las décadas siguientes pudieron conseguir plazas en las universidades, el prestigio social del profesorado universitario, en especial de los catedráticos (que eran los mejor remunerados), la dedicación plena a la investigación, la necesidad de viajar para acudir a congresos, etc., fueron factores que favorecieron que, como no encajaban con lo socialmente aceptado para las mujeres en el contexto dictatorial, el profesorado universitario estuviese compuesto mayoritariamente por hombres ${ }^{14}$.

\section{$\underline{2.2 \text { La extracción social y la formación académica }}$}

Las cuatro mujeres analizadas provenían de familias acomodadas, aunque no todas contaron con las mismas facilidades económicas. Que sus hermanos/as también tuviesen acceso a los niveles superiores de la enseñanza demuestra que, pese a las posibles dificultades, contaban con una situación económica favorable en comparación con el grueso de la sociedad española.

En primer lugar, María del Pilar Corrales Gallego nació el 30 de marzo de 1901 en Corrales, un pequeño pueblo zamorano, aunque el bachillerato lo realizó en el Instituto de Valladolid, terminándolo en 1917. Posteriormente accedió a la Universidad de Valladolid para cursar la licenciatura de Filosofía y Letras (Sección de Historia), la

\footnotetext{
${ }^{13}$ Ignacio PEIRÓ, "Catedráticos franquistas, franquistas catedráticos. Los «pequeños dictadores» de la Historia", Francisco CASPISTEGUI e Ignacio PEIRÓ (eds.), Jesús Longares Alonso: el maestro que sabía escuchar, EUNSA, 2016, pp. 251-291; Gustavo ALARES, Las políticas del pasado en la España franquista (1939-1964). Historia, nacionalismo y dictadura, European University Institute, Florencia, 2014; Carolina RODRÍGUEZ, La Universidad de Madrid en el primer franquismo: ruptura y continuidad (1939-1951), Madrid, Dykinson, 2002.

${ }^{14}$ Ana GUIL y Consuelo FLECHA, "Universitarias en España: de los inicios a la actualidad", Revista Historia de la educación latinoamericana, 24 (2015), pp. 125-148, p. 137. Sobre la situación de las mujeres en el franquismo, por ejemplo: Aurora MORCILLO, En cuerpo y alma. Ser mujer en tiempos de Franco, Siglo XXI, 2015. Aunque estas situaciones cambian espacial y temporalmente: Marta VOHLÍDALOVÁ y Alice ČERVINKOVÁ, Vědci a vědkyně v pohybu: o akademické mobilitě, Praga, Sociologický ústav AV ČR, 2012.
} 
cual finalizó en el curso 1921-1922. De todas las mujeres estudiadas, Pilar fue la que peores calificaciones tuvo, ya que siquiera llegó a alcanzar el notable en la nota media final. Asimismo, sus dos hermanas también se licenciaron, una en Derecho y otra en Filosofía y Letras, mientras que su hermano fue Capitán del ejército y, durante la dictadura de Primo de Rivera, ejerció como delegado gubernativo ${ }^{15}$.

En segundo lugar, Matilde Moliner Ruíz, la hermana pequeña de María Moliner, nació en Madrid el 7 de julio de 1904. La biografiada se crió en un ambiente liberal, dentro de una familia desahogada económicamente y en la que imperaba una relativa igualdad entre los sexos (lo cual era algo imaginable y aceptable para las familias de este tipo de posición social). Sin embargo, cuando su padre les abandonó, el resto de la familia comenzó a tener problemas económicos y tuvieron que trasladarse a Aragón para tener el apoyo material de la familia materna. Esta mala situación económica provocó que Matilde tuviese que abandonar la Institución Libre de Enseñanza (ILE), donde había cursado la Primaria. Sin embargo, el haber estudiado en dicha institución le marcó para toda la vida, como lo demuestra que en su posterior labor como docente adoptase como propios los modernos e innovadores postulados educativos fomentados por la ILE ${ }^{16}$.

Posteriormente, pese a las dificultades económicas de su familia, Matilde consiguió estudiar el Bachiller en el Instituto de Valladolid y, junto con su hermano Enrique y su hermana María, consiguieron planificarse para examinarse por turnos en la universidad, al no poder pagar todas las tasas de matrícula a la vez. De esta manera, Matilde Moliner se licenció en Filosofía y Letras (Sección de Historia) por la Universidad de Zaragoza (aunque comenzó los estudios en Valencia), en el curso 1924-1925, obteniendo unas calificaciones muy destacadas. De hecho, acabó consiguiendo el Premio Extraordinario de la Sección de Historia ${ }^{17}$. Me gustaría resaltar que el esfuerzo que realizaron Matilde y María para cursar estudios universitarios pudo

\footnotetext{
15 Archivo general de la Universidad Complutense de Madrid (AGUCM), EA-130; El defensor de Córdoba, 15 de julio de 1924, p. 4; La Voz, 9 de septiembre de 1927, p. 3; El Adelanto, 12 de abril de 1928, p. 6; Diario de León, 17 de junio de 1928, p. 8; Diario de León, 11 de julio de 1928; Diario de León, 23 de julio de 1928, p. 8.

${ }^{16}$ Inmaculada de la FUENTE, Las republicanas "burguesas", España, Sílex, 2015, p. 151. También en el resto de historiadoras estudiadas se aprecian, directa e indirectamente, las huellas del institucionismo, especialmente debido a su vinculación con la JAE.

17 AGUCM, EA-158.
} 
estar estimulado, por un lado, porque el abandono del padre reafirmaría a la madre en la necesidad de que sus hijas tuviesen una carrera para poder sostenerse a sí mismas $y$, por otro lado, porque en la lucha por mantener su estatus, la familia optaría por movilizar todos sus recursos disponibles para facilitar que tuviesen carreras (la burguesía profesional más precaria era la menos reticente al trabajo femenino cualificado).

En tercer lugar, María Luisa González nació el 24 de agosto de 1900 en un pequeño pueblo de la provincia de Burgos llamado Medina de Pomar, aunque trasladó en muchas ocasiones su residencia habitual. Se crió en el seno de una familia culta en la que se valoraba positivamente que todos sus miembros tuviesen educación, y en la que a su padre (un boticario-farmacéutico) y a su madre les parecía bien que siguiese estudiando. Sin embargo, todavía siendo joven quedó huérfana de ambos padres. Esto, como en el caso de Matilde, pudo ser un incentivo externo a que las hijas de la familia tuviesen una preparación elevada encaminada a desarrollar posteriormente una carrera profesional $^{18}$.

María Luisa terminó con notas excelentes el bachillerato en el Instituto de Albacete (aunque lo había empezado en Soria). Tras finalizar estos estudios se marchó con su hermana Ernestina a Salamanca con el fin de ingresar en la universidad local, algo que pudo conseguir gracias a la ayuda de una beca. Allí se licenció con calificaciones excelentes en Filosofía y Letras (Sección de Letras) en el curso 1920$1921^{19}$. Posteriormente, María Luisa estuvo viviendo algún tiempo en la Residencia de Estudiantes y en el Instituto Internacional (cuando estuvo preparando unas oposiciones), gracias a que disfrutó de una ayuda que le permitió sufragar parte de los gastos. María Luisa al final de su vida daba gran importancia al impacto que tuvo sobre su persona este lugar, al ser un espacio de libertad ideal para el desarrollo intelectual de las mujeres:

\footnotetext{
${ }^{18}$ De hecho sus hermanas también tuvieron acceso a estudios superiores, llegando a ser la mayor, Ernestina, la primera catedrática de Geografía en la Escuela Normal de Salamanca: Entrevista oral a María Luisa González. Proyecto de investigación fuentes orales de la Residencia de Estudiantes (1990). Archivo de la Residencia de Estudiantes (ARE).

${ }^{19}$ AGUCM, EA-147; Blanca CALVO y Ramón SALABERRÍA, "Juan Vicens, inspector de Bibliotecas Públicas Municipales (1933-1936)”, Educación y biblioteca, 169(2009), pp. 106-107.
} 
"[En la Residencia] Las personas, tanto hombres como mujeres, teníamos el mismo derecho a tener nuestra carrera, nuestra salida, en cierto modo un poco feminista era [...], de que la mujer realizara el papel que podía tener en la sociedad ilustrándose y cultivándose [...]. [Lo más importante de todo era que allí podías] cultivarte para poder tener un papel, no en la familia, sino para proyectarte al exterior"20.

Además, en cuanto a las relaciones personales entre hombres y mujeres establecidas en la Residencia de Estudiantes afirmaba que:

"Nos dejaban pasar la noche fuera porque sabian perfectamente que no pasaba nada, las costumbres eran otras [...]; ni ellos se atrevían ni nosotras lo hubiéramos consentido [...]. [Además] ellos en aquella época tampoco sabían hacer el amor, y nosotras tampoco, así que... [...] podríamos haber hecho el amor, pero ni se pensaba. [...]. [Sin embargo, todavía había] un pensamiento bastante machista, aunque lo cierto es que no queríamos ser feministas [...]. Eso de separarme del hombre no"21.

Por último, Amada López nació el 20 de junio de 1906 en Los Nogales, un pequeño pueblo de la provincia de Lugo. Aunque también fue huérfana de padre desde su niñez, parece que siempre mantuvo una situación económica bastante desahogada, ya que su madre realizó constantes donaciones para diversos fines benéficos y porque, durante el tiempo en el que fue pensionada en París por la JAE, no le preocupaba en exceso que le llegasen con retraso los fondos mensuales correspondientes a la pensión. Además, algunos de sus familiares tuvieron un buen posicionamiento social; por ejemplo su tío fue Decano del Cuerpo Médico Farmacéutico de la Beneficencia Provincial de Madrid. Tras finalizar brillantemente sus

\footnotetext{
${ }^{20}$ Entrevista oral a María Luisa González. Proyecto de investigación fuentes orales de la Residencia de Estudiantes (1990). ARE. Todas las entrevistas que le realizaron fueron producidas al final de su vida. Debido a que estas fuentes podían ofrecer conocimiento inaccesible mediante otros medios, las he utilizado teniendo presente que la memoria es eminentemente subjetiva y está filtrada por los acontecimientos y reflexiones realizadas posteriormente. Sobre esto: Enzo TRAVERSO, El pasado. Instrucciones de uso. Historia, memoria, política, Marcial Pons, 2007. Sobre la Residencia de Estudiantes y la Residencia de Señoritas, por ejemplo: Isabel PÉREZ-VILLANUEVA: La residencia de estudiantes. Grupo Universitario y de señoritas. Madrid, 1910-1936, Madrid, Ministerio de Educación y Ciencia, 1990.

${ }^{21}$ Entrevista oral a María Luisa González. Proyecto de investigación fuentes orales de la Residencia de Estudiantes (1990). ARE. Considero interesante resaltar que María Luisa tuvo una gran amistad con muchos de los intelectuales presentes entonces en la Residencia, sobre todo con Lorca, Buñuel, Moreno Villa y Dalí. De hecho, era habitual que estuviese con ellos cuando debatían sobre cuestiones académicas. Sin embargo, a diferencia de lo que afirman algunas/os historiadoras/es, no perteneció a la Orden de Toledo; el nombre con el que se autobautizaron aquellos residentes, como Buñuel o Lorca, que solían acudir a Toledo en su tiempo de ocio.
} 
estudios del bachillerato en el Instituto de Lugo, Amada se trasladó en solitario a cursar estudios universitarios a Madrid, donde vivió de alquiler en varias residencias. Finalmente se licenció en Filosofía y Letras (Sección de Historia) por la Universidad Central de Madrid con un expediente extraordinario ${ }^{22}$. Que estas mujeres tuviesen un gran rendimiento académico es importante, porque uno de los elementos que ayudaron en el proceso de normalización de las mujeres universitarias fue el reconocimiento académico e intelectual que lograron algunas de ellas.

\section{$\underline{2.3 \text { La trayectoria laboral }}$}

Como ya adelanté, la práctica totalidad de mujeres investigadoras en Historia acabaron optando, más tarde o más temprano, por tratar de asegurarse su futuro laboral intentando convertirse en docentes de Institutos de segunda enseñanza o en miembros del CFABA. De las cuatro mujeres analizadas, María del Pilar y María Luisa se inclinaron por realizar las oposiciones al CFABA, mientras que Amada y Matilde se decantaron por conseguir plaza en Institutos de segunda enseñanza. Por tanto, pese a que las cuatro se licenciaron en un momento en el que se estaba ampliando el número de actividades profesionales que eran desempeñadas por mujeres de clase media con títulos universitarios ${ }^{23}$, estas historiadoras no eligieron trayectorias profesionales que se alejasen mucho de lo que podría ser socialmente aceptado. Sin embargo, todas tuvieron que seguir enfrentándose a situaciones muy difíciles e injustas.

\footnotetext{
22 JAE, "Expediente de López Meneses, Amada", Expediente JAE/87-283; J. GOYANES, "Carta remitida por Goyanes, J.", PS. Madrid. 639/165. Centro Documental para la Memoria Histórica (CDMH); El imparcial, 9 de mayo de 1912; El Progreso. Diario liberal, 20 de enero de 1923, p. 2; El Progreso. Diario liberal, 23 de marzo de 1923, p. 3; María POVEDA SANZ, Mujeres y segunda enseñanza en Madrid (1931-1939). El personal docente femenino en los institutos de bachillerato, Tesis Doctoral, UCM, Madrid, 2014, p. 91.

${ }^{23}$ Consuelo FLECHA, "Itinerarios académicos de mujeres en la universidad española", Josefina CUESTA, María Luz DE PRADO y Francisco J. RODRÍGUEZ (dirs.), ¿Mujeres sabias? Mujeres universitarias en España y América Latina, Pulim, 2015, p. 59.
} 


\subsubsection{La trayectoria profesional de quienes optaron por entrar al Cuerpo}

\section{Facultativo de Archiveros, Bibliotecarios y Arqueólogos}

Tanto María del Pilar Corrales como María Luisa González optaron, nada más terminar sus licenciaturas, por presentarse a las oposiciones al CFABA de 1922, en las cuales tuvieron éxito y pudieron obtener plaza. Este Cuerpo estaba comenzando un proceso de feminización cuando estas mujeres se incorporaron al mismo, ya que la primera mujer había entrado apenas una década antes. De todas formas, todavía las mujeres que se incorporaban tenían que enfrentarse a ciertas resistencias y oposiciones, especialmente porque las trataban de relegar a las escalas más bajas del escalafón, que eran los puestos con menor remuneración, menores responsabilidades y más reducido prestigio social ${ }^{24}$.

En el caso de Pilar, tras hacer las prácticas correspondientes fue destinada a la Biblioteca del Instituto de Mahón (Menorca), aunque inmediatamente tuvo una excedencia de su cargo para poder disfrutar de la equiparación de pensionada que le concedió la JAE. Tras regresar a España, pese a que contrajo matrimonio con un acaudalado propietario e industrial barcelonés en 1930, trabajó en varias bibliotecas y archivos de Baleares, de León y de Cataluña. En estos lugares ganó un prestigio que le sirvió para llegar a participar en la presidencia de actos de homenaje a colegas de profesión, como en el caso del homenaje al prestigioso historiador Pedro Riaño de la Iglesia ${ }^{25}$.

De las mujeres biografiadas, fue Pilar Corrales quién menos se vio afectada por la victoria del bando sublevado en la guerra civil. Pese a que se le abrió un expediente de depuración por parte de la Comisión Depuradora de Educación Nacional de Barcelona durante el transcurso de la guerra por la sospecha de que tuviese alguna conexión con las redes masónicas, el proceso no avanzó y, en consecuencia, no fue

\footnotetext{
${ }^{24}$ Revista de archivos, bibliotecas y museos, 1 de julio de 1922, p. 150. Para mayor información sobre el CFABA: Agustín TORREBLANCA LÓPEZ, El Cuerpo Facultativo de Archiveros, Bibliotecarios y Arqueólogos. (1858-2008). Historia burocrática de una institución sesquicentenaria, Ministerio de Cultura, 2009, pp. 105-108 y 120-121.

${ }^{25}$ Revista de archivos, bibliotecas y museos, 1 de octubre de 1924, p. 103; La Libertad, 24 de diciembre de 1924, p. 4; Gaceta de Madrid, 5 de marzo de 1925, p. 1070; Gaceta de Madrid, 20 de marzo de 1925, p. 1430; Gaceta de Madrid, 30 de marzo de 1925, p. 1607; Diario de León, 30 de enero de 1928; Diario de León, 26 de agosto de 1929, p. 8; Diario de León, 16 de noviembre de 1929, p. 8; Diario de León, 22 de enero de 1930, p. 5; Diario de León, 5 de agosto de 1931, p. 1 y Gaceta de Madrid, 27 de febrero de 1933, p. 1578.
} 
sancionada de ninguna manera. Por tanto, se mantuvo ininterrumpidamente en su cargo como administradora de una biblioteca-museo en Vilanova, hasta que a finales de los años cuarenta decidió abandonar el puesto. Posteriormente combinó diversos traslados y excedencias, hasta que a finales de los años cincuenta fue destinada a las bibliotecas de la Universidad de Barcelona. Allí desempeñaría durante muchos años el cargo de bibliotecaria-jefe de la biblioteca de la Facultad de Medicina y, además, Ilegaría a ser la directora provisional de la Biblioteca Universitaria y Provincial de Barcelona entre 1965 y 1966. Por tanto, Pilar Corrales dedicó toda su vida profesional al CFABA, hasta que en 1971 le llegó la hora de jubilarse. Por último, cabe destacar que esta mujer también tuvo presencia destacada, como parte de la delegación oficial española, en los diversos Congresos de la Federación Internacional de Asociaciones de Bibliotecarios y Bibliotecas ${ }^{26}$.

El caso de María Luisa fue muy diferente. Después de licenciarse comenzó a preparar oposiciones para tratar de obtener una plaza en el CFABA. Tras conseguirla y realizar las prácticas correspondientes comenzó a trabajar en la misma Biblioteca provincial de León que años después dirigió Pilar Corrales. Sin embargo, nunca llegaron a coincidir porque en los años posteriores, y hasta el comienzo de la guerra, fue trasladada por diversos lugares de la geografía española, aunque sobre todo tuvo destinos en Madrid. Sin embargo, el comienzo de la guerra civil le trastocó la vida. Tras conseguir una excedencia de su puesto de funcionaria se exilió a Francia, pero en plena ofensiva alemana sobre aquél país su marido y ella tomaron caminos diferentes: Juan Vicens fue hacia México mientras que María Luisa y sus hijos, entonces de 10 y 12 años, se trasladaron a la URSS, llegando en el último contingente de adultos que

\footnotetext{
${ }^{26}$ Comisión Depuradora de Educación Nacional de Barcelona, "Ficha de María del Pilar Corrales Gallego", Expediente de depuración 69. Legajo 1318. CDMH; BOE, 12 de octubre de 1948, p. 1793; BOE, 16 de mayo de 1957; Boletín de la Dirección General de Archivos y Bibliotecas, 30 de abril de 1966, 88, p. 20; La Vanguardia, 18 de septiembre de 1969, p. 20; Boletín de la Dirección General de Archivos y Bibliotecas, 31 de agosto de 1971, 119, p. 50; Boletín de la Dirección General de Archivos y Bibliotecas, 28 de febrero de 1967, p. 20; Boletín de la Dirección General de Archivos y Bibliotecas, 30 de abril de 1968, p. 116; Boletín de la Dirección General de Archivos y Bibliotecas, 31 de octubre de 1969, p. 55; Montserrat ALÒS PLA, "La funció i la gestió de l'Organisme Autònom Local de Patrimoni "Víctor Balaguer", Butlletí de la Biblioteca Museu Balaguer, 1 (2008), pp. 62-63; Francesc PUIG ROVIRA, "Memòria de Teresa Basora", Reembres, 17 (1998), pp. 6-7.
} 
acabó en tierras soviéticas. En consecuencia, todo el peso de las tareas de cuidados recayó en ella. Sobre esto profundizaré posteriormente ${ }^{27}$.

Durante sus primeros dos años en la URSS ejerció como maestra de los adolescentes españoles que habían sido trasladados allí. Después, en 1943, creó la Cátedra de Lengua Española dentro del Instituto Estatal de Relaciones Internacionales de Moscú, donde se preparaba a los diplomáticos, convirtiéndose en jefa de esa cátedra. Sin embargo, como el ambiente reinante en esa institución no le resultaba cómodo, pronto prefirió trasladarse a trabajar como docente en la Universidad Lomonosov de Moscú ${ }^{28}$. En ese lugar creó la primera Cátedra de Literatura Española en la URSS:

"En la universidad me habian dicho [...] que siempre es más proletaria [...] que en la universidad, hiciese lo que hiciese, no me pasaría nada [...]. Entonces estuve en la Universidad [...] pero yo daba a los maestros, y después a los alumnos [...] mayores"29.

Varios años después abandonó la URSS para trasladarse a China junto a Juan Vicens (que acababa de dejar México), donde también organizó una Cátedra de Literatura Española en la Universidad de Pekín. Pero tras fallecer su marido en 1959, en 1962 decidió volver a Moscú, ya que le habían mantenido reservada la Cátedra de la universidad y sus hijos estaban allí. Tras pasar media vida en la URSS y en China,

\footnotetext{
27 JAE, "Expediente de González Rodríguez, María Luisa", Expediente JAE/73-793; Gaceta de Madrid, 17 de febrero de 1923, p. 686; La Época, 5 de diciembre de 1923; La Voz de Menorca, 8 de mayo de 1926; Diario de León, 23 de junio de 1928, p. 1; Gaceta de la República, 13 de enero de 1938, p. 188; Ramón SALABERRÍA, "Las bibliotecas populares en la correspondencia de Juan Vicens a Lulu Jourdain y Hernando Viñes (1933-1936)", Anales de documentación: Revista de biblioteconomía y documentación, 5 (2002), p. 330; María Encarna NICOLÁS MARÍN, "La integración de los niños y jóvenes en la emigración de la Guerra civil: El caso de la Unión Soviética", Anales de Historia Contemporánea, 19 (2003), pp. 65-66; Entrevista oral a María Luisa González. Proyecto de investigación fuentes orales de la Residencia de Estudiantes (1990). ARE. Que María Luisa optase por la URSS no es extraño ya que tenía ideas cercanas al socialismo (e incluso su marido militó en el PCE). María Luisa ya había mostrado públicamente sus preferencias ideológicas al firmar el "Manifiesto sobre la Alemania de Hitler" cuando en 1933 el dictador nazi llegó al poder. Sin embargo, lo hizo bajo el nombre de María Luisa Vicens, lo cual pudo ser una táctica para negociar con las normas de género de la época porque así se entendía que contaba con el apoyo de su marido para firmar la proclama. De todas formas siempre fue crítica con la ortodoxia del sistema soviético, al creer que el partido debía ser democrático desde el punto de vista de su estructura y que era deseable un cierto pluralismo que generase polémicas. Ian GIBSON, El asesinato de García Lorca, Plaza y Janés, 1996, pp. 316-318.

${ }^{28}$ Entrevista oral a María Luisa González. Proyecto de investigación fuentes orales de la Residencia de Estudiantes (1990). ARE.

${ }^{29}$ Entrevista oral a María Luisa González. Proyecto de investigación fuentes orales de la Residencia de Estudiantes (1990). ARE.
} 
María Luisa decidió regresar en 1977 a España, una vez que había empezado el desmantelamiento de la dictadura franquista ${ }^{30}$.

\subsubsection{La trayectoria profesional de las que optaron por dedicarse a la enseñanza secundaria}

Matilde y Amada apostaron por un camino profesional diferente al de Pilar y María Luisa para ganarse la vida: el de ser profesoras de segunda enseñanza. Aunque como ya mostré era una opción muy habitual entre las historiadoras.

En el caso de Matilde Moliner, tras ser colaboradora en el Estudio de Filología de Aragón para sufragarse los estudios y contribuir a los gastos familiares, impartió clases en institutos de Sagunto, Requena, Murcia, Talavera de la Reina y Madrid (donde ligaría su nombre, desde el curso 1933-1934, al Instituto Cervantes). Además, durante el tiempo que estuvo en Murcia, Matilde se convirtió en ayudante de clases prácticas en la Universidad de aquella provincia en la Facultad de Filosofía y Letras (curso 1925-1926), justo antes de trasladarse a Madrid para cursar el Doctorado mientras trabajaba ${ }^{31}$.

Sin embargo, Matilde no sólo vinculó su vida a la enseñanza, ya que su amor por la cultura le llevó a implicarse a fondo en las Misiones Pedagógicas y a colaborar con bibliotecas, llegando a priorizar su labor en estos ámbitos sobre su interés investigador personal. Su trabajo en las Misiones Pedagógicas fue diverso, pero destaca que fuese una de las artífices de la organización y de la selección de los libros de las primeras Bibliotecas Circulantes (tarea que desempeñó junto a personajes ilustres como Antonio Machado y Luis Cernuda). También tuvo diferentes cargos de

\footnotetext{
${ }^{30}$ Entrevista oral a María Luisa González. Proyecto de investigación fuentes orales de la Residencia de Estudiantes (1990). ARE; Galina ROMANOVA, "Un poco sobre la enseñanza del español en Rusia", Sara SAZ (ed.), Retos para un nuevo milenio: lengua, cultura y sociedad. Actas del Coloquio Internacional de la Asociación Europea de Profesores de Español, Fort Collins, Colorado State University, 2000, pp. 75-80; Violetta BENCHIK, "De la escuela a la Universidad: continuidad en la enseñanza de las variedades diatópicas del español en Rusia”, FIAPE. V Congreso internacional: ¿Qué español enseñar y cómo? Variedades del español y su enseñanza, Cuenca, 25-28 de junio de 2014; Miguel MORA: "El bibliotecario del 27 y la pionera risueña", El País, 6 de abril de 1999.

${ }^{31}$ JAE, "Expediente de Moliner Ruíz, Matilde", Expediente JAE/100-653; Inmaculada de la FUENTE, Las republicanas...", op. cit., p. 152; Consuelo FLECHA, "Institutos de Segunda Enseñanza en España, y primeras profesoras en los de Murcia", VVAA., Homenaje al profesor Alfonso Capitán, Universidad de Murcia, Servicio de Publicaciones, 2005, pp. 179-180; Gaceta de Madrid, 27 de junio de 1933; Gaceta de Madrid, 24 de diciembre de 1931, pp. 1905-1906; El Sol, 16 de octubre de 1928, p. 2; Las provincias, 24 de octubre de 1928, p. 4; Guía oficial de España. 1929, p. 788.
} 
responsabilidad en la organización, llegando a formar parte de la presidencia de la Comisión Central que dirigía el Patronato de Misiones Pedagógicas, y participó en varias misiones específicas: dirigió la gira que se hizo en marzo-abril de 1933 por Murcia y actuó como misionera en Navalcán (Toledo), Valdepeñas de la Sierra (Guadalajara) y Bustarviejo (Madrid). Además, durante la segunda república Matilde Moliner fue socia del Ateneo de Madrid, miembro de la Asociación de Doctores y Licenciados Profesores de Institutos y participó en 1935, como personalidad destacada, en el Congreso Internacional de Bibliotecas y Bibliografía que se celebró en España $^{32}$.

Pero desgraciadamente toda esta actividad cultural le pasó factura durante la guerra civil, por lo que vio afectada mucho su trayectoria profesional y personal. Tras trasladarse durante la guerra a Valencia, donde dirigió la biblioteca de la universidad local e impartió clases en el Instituto Blasco lbáñez, fue investigada por el bando sublevado tanto en Madrid (donde se la absolvió) como en Valencia (donde se la inhabilitó), porque fue señalada, en una declaración jurada de Julián Cebrián Narro, como una persona claramente republicana y de izquierdas que frecuentaba los círculos intelectuales y políticos republicanos ${ }^{33}$. La inhabilitación que sufrió en Valencia provocó que hasta 1941 no pudiese volver a ejercer la docencia. En esa fecha empezó a trabajar en un instituto de Benicarló (aunque sin posibilidad de ejercer cargos directivos) y, poco después, se trasladó a un puesto docente en Almería, que era

\footnotetext{
${ }^{32}$ Crisol, 10 noviembre 1931, p. 12; Gaceta de Madrid, 8 de marzo de 1933, p. 1829; La Época, 8 de marzo de 1933, p. 3; ABC, 9 de marzo de 1933, p. 36; Defensor de Albacete, 14 de marzo de 1933, p. 2; La Región de Murcia, 1 de abril de 1933, p. 1; La Verdad de Murcia, 1 de abril de 1933, p. 2; El Tiempo, 1 de abril de 1933, p. 3; ABC, 25 de abril de 1935, p. 48; Gaceta de Madrid, 10 de abril de 1935, p. 264; ABC, 11 de abril de 1935, p. 34; Heraldo de Madrid, 25 de abril de 1935, p. 5; El Sol, 25 de abril de 1935, p. 2; Etelvino GONZÁLEZ LÓPEZ, "El pedagogo Luis Álvarez Santullano", Cuadernos de la Cátedra Miguel de Unamuno, 48 (2010), p. 124; Chus CANTERO, El concepto de la extensión universitaria a los largo de la historia, Sevilla, Dirección General de Universidades, 2006, p. 73; Pedro Luis MORENO MARTÍNEZ, "Las misiones pedagógicas en Murcia a través de su legado fotográfico (1933-1935)", Actas del XVIII Coloquio de Historia de la Educación: Arte, literatura y educación, 2, 2015, pp. 397-398; Josefa OTERO, "Matilde Moliner...", op. cit., pp. 115-126; Memoria de 1959 del Consejo Superior de Investigaciones Científicas; "El claustro del instituto Cervantes de Madrid solicita la rehabilitación de Antonio Machado como catedrático", El País, 19 de diciembre de 1981, recuperado de http://elpais.com/diario/1981/12/19/cultura/377564402 850215.html.

33 Josefa OTERO, “Matilde Moliner...", op. cit., pp. 115-126; María POVEDA, Mujeres y segunda enseñanza..., op. cit., pp. 553-554. De hecho, el gobierno de la segunda república la reafirmó en varias ocasiones con plenitud de derechos como parte del servicio activo del cuerpo de Profesores de Segunda Enseñanza: Gaceta de la República, 6 de agosto de 1937, pp. 494-495; Gaceta de la República, 6 de enero de 1938, p. 72.
} 
donde se encontraba su marido. Posteriormente regresaría al Instituto Cervantes de Madrid, donde impartió clases en calidad de catedrática de Historia desde 1952 hasta que se jubiló en 1974. Poco antes de la jubilación, un Claustro Extraordinario aprobó solicitar al Ministerio el ingreso de Matilde en la Orden Civil de Alfonso X El Sabio en la sección "Al mérito Docente". Sin embargo era difícil que por su afinidad a la segunda república le concediesen aquél galardón franquista; y de hecho no se lo otorgaron ${ }^{34}$.

Asimismo, Amada López, que fue quién mayor labor de investigación histórica realizó de las cuatro biografiadas, también tuvo una trayectoria profesional no lineal. Aunque, en vez de deberse a constantes traslados de centro (como le ocurrió a Matilde), fue una trayectoria discontinua por las constantes excedencias que pidió para realizar investigaciones históricas y porque, como tuvo grandes problemas durante el franquismo, tardó mucho tiempo en volver a normalizar su situación como profesora de Institutos Nacionales de Enseñanza Media: sólo a mitad de los años cincuenta pudo volver a desarrollar su labor docente debido a que fue entonces cuando finalmente se la declaró depurada sin sanción ${ }^{35}$.

Por último, para cerrar este apartado quiero defender que, en base a todo lo mostrado, estas cuatro mujeres tuvieron una más que interesante y fructífera trayectoria profesional a pesar de todas las dificultades que tuvieron que superar. $Y$ eso que, en cierto modo, estaban más protegidas por su status social que aquellas españolas de las capas populares de la sociedad que intentaban realizar una trayectoria semejante a la suya. De todas formas, si tuvieron una carrera profesional exitosa se debió, fundamentalmente, a que fueron buenas trabajadoras que demostraron que sus capacidades intelectuales no dejaban nada que desear, que lo que aprendieron en la universidad eran capaces de aplicarlo en la práctica y a que España contaba con poca gente cualificada y no podía prescindir fácilmente de las personas que lo estaban.

\footnotetext{
${ }^{34}$ Josefa OTERO, “Matilde Moliner...", op. cit., pp. 115-126.

${ }^{35}$ Francisco José BARNÉS SALINAS, "Ficha de recomendado: López de Meneses, Amada", PS. Madrid. 635/3/8. CDMH; JAE, "Expediente de López Meneses, Amada", Expediente JAE/87-283; BOE, 15 de julio de 1955, p. 4283; La Vanguardia, 24 de octubre de 1929, p. 4; La Opinión, 17 de octubre de 1929; El Sol, 13 de marzo de 1930, p. 3; María POVEDA, Mujeres y segunda enseñanza..., op. cit., p. 172 y 476.
} 


\section{$\underline{2.4 \text { Desarrollo de la labor investigadora }}$}

Las trayectorias investigadoras de estas mujeres fueron muy variadas y tuvieron diferentes grados de éxito, especialmente porque algunas de ellas apenas pudieron desarrollar su carrera investigadora por diversos motivos.

En el caso de Matilde Moliner, una vez licenciada se trasladó a Madrid para comenzar el doctorado en la Universidad Central en el curso 1926-1927. Tras varios años realizando la tesis bajo la dirección del prestigioso historiador Rafael Altamira, en 1932 consiguió que la JAE le otorgase una pensión para profundizar en la investigación, aunque por diversas circunstancias no pudo llegar a disfrutarla. Era una pensión para que durante diez meses mejorase en Francia e Inglaterra, aprovechando que sabía francés, inglés y alemán, su tesis doctoral titulada "La intervención de Inglaterra en la independencia de las colonias hispano-americanas". Aunque nunca llegó a doctorarse, ni siquiera después de la guerra civil cesó su actividad investigadora: tras el conflicto bélico trabajó como investigadora en el Instituto Gonzalo Fernández de Oviedo, tomó parte del Primer Congreso Hispanoamericano de Historia en 1949 y finalmente pudo consultar los archivos parisinos y londinenses, lo que le posibilitó terminar su memoria de becaria en dicho instituto, la cual fue publicada en la Revista de Indias en 1953 bajo el título "Ingleses en los ejércitos de Bolivia: el Coronel Enrique Wilson" ${ }^{36}$.

También Pilar Corrales al terminar la licenciatura se marchó a Madrid para realizar la tesis doctoral. Poco después, en 1925, recibió una equiparación de pensionada por parte de la JAE para que durante un año realizase investigaciones históricas en París, aprovechando que sabía francés, con el fin de que enriqueciese su tesis titulada "Primera conjuración republicana en tiempos de Carlos IV". Durante su estancia en Francia, aparte de desarrollar una intensa actividad investigadora, gracias a las negociaciones de Menéndez Pidal tuvo acceso a los inéditos documentos de Morel-Fatio y Leonardon, cuya consulta hasta entonces había estado restringida. Cuando terminó su beca Pilar y el archivero jefe de la Biblioteca de Versalles pidieron a

\footnotetext{
${ }^{36}$ En la propia Revista de Indias publicó durante los años siguientes algunos artículos más de investigación histórica. JAE, "Expediente de Moliner Ruíz, Matilde", Expediente JAE/100-653; El Castellano, 10 de julio de 1933, p. 3; Josefa OTERO, "Matilde Moliner...", op. cit., pp. 115-126; Inmaculada de la FUENTE, El exilio interior. La vida de María Moliner, Turner, 2011.
} 
la JAE que se le renovase la pensión para que pudiese ordenar y catalogar los fondos que había consultado, con el objetivo final de crear allí un centro de estudios hispánicos. Sin embargo, esto fue rechazado por la JAE. Todo parece indicar que aquí finalizó su trayectoria investigadora, puesto que no presentó su tesis doctoral ni publicó ningún trabajo de investigación histórica ${ }^{37}$.

Muy diferente fue el caso de María Luisa González. Bajo la dirección de Aurelio Viñas (catedrático de la Sorbona) comenzó a realizar una investigación para su tesis sobre las relaciones entre los condados del Rosellón y de Cerdaña con Cataluña durante el siglo XVII. Entonces pidió a la JAE ser pensionada en Francia, aprovechando su conocimiento del idioma, para poder estudiar el tema con documentos inéditos. Aunque no consiguió lo que se proponía (una pensión completa) le fue concedida una equiparación a pensión durante un año en París, tiempo que aprovechó para profundizar en su investigación y presentar a la JAE, al finalizar el año, el trabajo titulado: "Incidentes ocurridos en los condados del Rosellón y Cerdaña durante los años 1640-1641", que tenía como fin demostrar el aprovechamiento de la beca $^{38}$.

Justo entonces María Luisa solicitó una prórroga de la pensión por diez meses más. Sin embargo no consiguió su objetivo debido a que la JAE comenzó a dudar de sus verdaderas intenciones y del interés científico de sus investigaciones, aunque contaba con la opinión favorable de Aurelio Viñas. La JAE interpretó que el verdadero objetivo de María Luisa, a quién siempre se referían como la señora de Vicens pese a su formación académica e intelectual, era prolongar su estancia en París debido a que allí se encontraba su marido ${ }^{39}$. Parece que la JAE estuvo en lo cierto porque al final de su vida María Luisa reconoció que nunca tuvo la intención de culminar la tesis doctoral:

"Al terminar [la licenciatura] yo era becaria de la universidad de Salamanca. La primera universitaria becada por oposición en la universidad de Salamanca. Pues la misma beca me pagaba, bueno, me pagaba una parte, de lo que yo gastaría en los estudios del doctorado en Madrid. Y vine a Madrid, pero no pensando en que iba a seguir los estudios del doctorado, porque como yo no tenía ni padre ni madre

\footnotetext{
${ }^{37} \mathrm{JAE}$, "Expediente de Corrales Gallego, María del Pilar", Expediente JAE/38-629.

${ }^{38}$ JAE, "Expediente de González Rodríguez, María Luisa", Expediente JAE/73-793.

39 JAE, “Expediente de González Rodríguez, María Luisa”, Expediente JAE/73-793.
} 
me tenía que ganar la vida pronto, y pensaba hacer oposiciones al Cuerpo [...] de Archivos, Bibliotecas y Museos",40.

De todas las biografiadas fue Amada López quién tuvo una carrera investigadora más larga y fructífera. Desarrolló una prolífica labor en términos de cantidad (publicó numerosos trabajos de investigación histórica) y también de calidad, ya que dentro de los modelos acordes a la historiografía de la época fue innovadora en algunos aspectos y temáticas. Amada fue pensionada por la JAE, en 1932, para que durante dos meses en París pudiese tratar de completar las investigaciones históricas que estaba desarrollando para la tesis doctoral, dirigida por los prestigiosos Antonio Ballesteros Beretta y Eduardo Ibarra y Rodríguez, la cual tenía como objeto de estudio el viaje de Margarita de Angulema (hermana del Rey Francisco I) a España. Como el periodo de tiempo que le concedió la JAE en París como becada era muy limitado para los ambiciosos objetivos que se había propuesto, decidió alargar la estancia en la capital francesa sufragándola de su bolsillo mediante la venta de algunas alhajas de valor que tenía (según lo que oficialmente indicó a la JAE). Esto, sumado a que poco después consiguió un trabajo como asistente de la lengua española en L'école normale supérieure de Fontenay-aux-Roses, le permitió quedarse en París el suficiente tiempo como para poder investigar en los archivos de Versalles, Chantilly y Fontainebleau ${ }^{41}$.

Tras regresar a España se convirtió en ayudante del Instituto Quevedo y tuvo una prolífica actividad como historiadora, publicando varios artículos monográficos en revistas de prestigio como el Boletín de la Real Academia de la Historia y el Bulletin hispanique, en las cuales publicaban algunos de los mejores y más prestigiosos historiadores españoles de la época. Esto se debió a que los trabajos históricos de

\footnotetext{
${ }^{40}$ Radio Televisión Española, "La Residencia de Estudiantes: Generación del 27, retrato de una época", 15 de octubre de 1983, Archivo de personajes, recuperado de http://www.rtve.es/alacarta/audios/personajes-en-el-archivo-de-rtve/residencia-estudiantes-generaciondel-27-retrato-epoca-parte-1/866906/. Archivo RTVE.

${ }^{41}$ Al regresar a España presentó dos monografías a la JAE sobre sus investigaciones en Francia. En ellas se aprecia la forma de trabajar de esta historiadora: minuciosa con las citas, utilizando no sólo fuentes archivísticas sino también bibliografía (en francés, español, inglés e italiano), memorias de los personajes de la época, fuentes literarias de diversa índole, etc. Por tanto, no pensaba que para los trabajos históricos sólo fuese de utilidad la búsqueda en el archivo de fuentes inexploradas e inéditas, lo que fue una actitud habitual en la comunidad de historiadores profesionales de la época. J. GOYANES, "Carta remitida por Goyanes, J.", PS. Madrid. 639/165. CDMH; JAE, "Expediente de López Meneses, Amada", Expediente JAE/87-283; Memoria de la Junta para Ampliación de Estudios e Investigaciones Científicas, Memoria correspondiente a los cursos 1933 y 1934, Madrid, 1935, pp. 92-94.
} 
Amada ya contaban con un amplio reconocimiento ${ }^{42}$. Tras la guerra continuó publicando muchos artículos y realizando diversas investigaciones, para las cuales estableció vínculos con varios centros de investigación, como el CSIC o el Instituto de Historia de Buenos Aires. Toda esta activa labor posibilitó que mantuviese durante el franquismo un prestigio intelectual entre sus colegas de profesión que le permitió, entre otras cosas, presentar una comunicación en el VI Congreso de Historia de la Corona de Aragón (1957), participar en actos de homenaje a colegas de profesión o encabezar algunas reivindicaciones para mejorar el Archivo general de Simancas. Pero, lo que es más importante de todo, es que este reconocimiento posibilitó que fuese nombrada miembro de la Real Academia Gallega en $1942^{43}$.

Además, los trabajos de Amada han sido de referencia obligatoria en las obras posteriores de los temas que estudió. Esta historiadora es considerada por los propios expertos como una pionera en el estudio de los gitanos en España, de las incidencias de la peste negra en los territorios de la Corona de Aragón (aunque sus análisis priorizasen, como era habitual en la época, los aspectos políticos sobre sus consecuencias sociales) y del linaje Moctezuma ${ }^{44}$.

\footnotetext{
${ }^{42}$ Por ejemplo: $A B C, 17$ de junio de 1932, p. 35; El Sol, 10 de marzo de 1936, p. 7; Boletín de la Dirección General de Archivos y Bibliotecas, 31 de octubre de 1963, p. 71. Es necesario resaltar que Amada consiguió prestigio por parte de sus pares en unos contextos, antes y después de la guerra civil, en los que era muy difícil para las historiadoras obtenerlo, debido a su escaso número, a su posición subalterna en la academia ("el techo de cristal") y a las dificultades que tenían para que los catedráticos que dirigían las revistas especializadas las considerasen capaces de producir textos de calidad. Tras la guerra, Amada siguió publicando en revistas de éxito, como por ejemplo en Hispania: Revista española de historia. Aunque hay que tener en cuenta que en los años cuarenta firmó algunos artículos como Magdalena Sáez Pomés.

${ }^{43}$ Boletín de la Dirección General de Archivos y Bibliotecas, 30 de junio de 1958, p. 39; La Vanguardia, 6 de marzo de 1969, p. 51; ABC, 23 de julio de 1931, p. 32; Heraldo de Madrid, 25 de julio de 1931, p. 6; Crisol, 25 de julio de 1931, p. 1. Esta académica fue propuesta para la Real Academia Gallega por Gonzalo Brañas, José Baldomir y el historiador Francisco Vales: Boletín de la Dirección General de Archivos y Bibliotecas, 30 de junio de 1958, p. 39.
}

${ }^{44}$ Algunos/as expertos/as consideran que sus trabajos sobre estos temas son de referencia obligada, por ejemplo: María Helena SÁNCHEZ ORTEGA, "Los gitanos españoles desde su salida de la India hasta los primeros conflictos en la península", Espacio, tiempo y forma. Serie IV, Historia moderna, 7 (1994), p. 327; Jesús SALINAS, "Un viaje a través de la historia de la escolarización de las gitanas y gitanos españoles", Anales de Historia Contemporánea, 25 (2009), p. 168; Juan de Dios RAMIREZ HEREDIA, " Salud y libertad' piden los gitanos en la India", La Vanguardia, 21 de mayo de 1976, p. 54; José Luis BETRÁN, "La peste como problema historiográfico", Manuscrits: Revista d'història moderna, 12 (1994), p. 311; Marcelino V. AMASUNO, "Referencias literarias castellanas a una peste del siglo XV", Revista de literatura medieval, 2 (1990), pp. 115-116; José TRENCHS, "La diócesis de Zaragoza y la peste de 1348", Cuadernos de historia Jerónimo Zurita, 25-26 (1972-1973), p. 119; Miguel LUQUE, "'Tan príncipes e infantes como los de Castilla': análisis histórico-jurídico de la nobleza indiana de origen prehispánico", Anales del Museo de América, 12 (2004), p. 15. 
Sin embargo, pese a que las cuatro historiadoras estudiadas recibieron pensiones o equiparaciones de pensión para que enriqueciesen sus tesis y consiguieron ciertos éxitos en el ámbito de la investigación, ninguna llegó a defender su tesis doctoral, al menos antes de 1954. Esto no es de extrañar porque las mujeres españolas tuvieron muchas dificultades en el acceso al doctorado. De hecho, sólo se empezó a equilibrar el porcentaje de doctorandos y doctorandas en fechas muy recientes $^{45}$. De todas formas, el que las cuatro lograsen ser becadas por la JAE suponía un reconocimiento a su trayectoria académica y profesional. Esto implicaba que la institución liberal les consideraba como capital intelectual del país y como capaces de contribuir, en calidad de profesionales e intelectuales, a la prosperidad y al desarrollo de España.

\subsection{La incidencia del matrimonio e hijos en la vida profesional}

La diferenciación social de los roles de género durante la época en la que estas historiadoras desarrollaron su vida profesional, justificados sobre la base supuestamente biológica de cada sexo, otorgaba a las mujeres el cuidado de los hijos, la realización de las labores del hogar y la representación social del marido (la idea de la perfecta anfitriona en España fue importante para las clases altas y medias-altas). Las mujeres que cumplían este ideal ocupaban en dichas tareas todo su tiempo, lo que les impedía desarrollar cualquier trabajo remunerado que no fuese un simple complemento del salario de su marido. Por tanto era un modelo de mujer que dificultaba que las españolas llegasen a ser profesionales de la investigación. Pero incluso las mujeres, como estas historiadoras, que siempre tuvieron un empleo asalariado a tiempo completo (también tras casarse y tener hijos, las que los tuvieron), no pudieron escapar totalmente de los roles que les eran asignados socialmente. En consecuencia, es de interés el estudio de estos elementos en las biografías de mujeres, pero siempre partiendo de la base de que la vida privada tenía más vertientes que su posible condición de esposas y madres. La información que proporcionan las fuentes disponibles sobre estos aspectos de la vida de las historiadoras estudiadas es

\footnotetext{
${ }^{45}$ María Jesús MATILLA, "Las primeras doctoras universitarias en España (1882-1954). La Facultad de Filosofía y Letras", Josefina CUESTA, María Luz DE PRADO y Francisco J. RODRÍGUEZ (dirs.), ¿Mujeres sabias? Mujeres universitarias en España y América Latina, Pulim, 2015, pp. 110-111 y 115119.
} 
escasa, aunque haciendo preguntas adecuadas a los documentos se puede obtener la suficiente información como para realizar un análisis parcial de cómo influyó la vida privada de estas mujeres a su trayectoria profesional e investigadora.

La profesora Matilde Moliner contrajo matrimonio durante la segunda república con Juan Arévalo y Cárdenas, licenciado también en Filosofía y Letras. Juntos tuvieron dos hijas; la primera nació durante la guerra civil y la segunda en la postguerra, pero desconozco si sus cuidados repercutieron en la vida profesional de Matilde. Lo que sí es evidente es que, cuando estuvo alejada de su marido por motivos laborales (no siempre trabajaron en la misma provincia), como siempre mantuvo a su cargo a las hijas tendría que realizar una intensa doble jornada de trabajo al tener que responsabilizarse, por un lado, de su profesión como docente y, por otro lado, de las tareas de cuidados a las hijas y de las labores del hogar. Sin embargo, sí que hay constancia de que durante su juventud tuvo que renunciar a algunos objetivos profesionales e intelectuales por tener que estar al cuidado de su madre enferma, mientras que se desconoce si su hermano o su hermana tuvieron también que renunciar a algo por ello ${ }^{46}$.

Muy interesante también fue el caso de María Luisa, de quién además se han conservado fuentes adecuadas para el estudio de esta problemática. Ella fue, de las cuatro biografiadas, quién mantuvo una posición más discordante ante los roles de género asignados a las mujeres en la época, por lo que desarrolló una serie de acciones encaminadas a superar las convenciones sociales. Pero, a su vez, en ella se aprecian también claramente las contradicciones habituales que sufrieron las mujeres de este perfil, ya que nunca llegó a transgredir lo socialmente aceptado. La licenciada contrajo matrimonio con Juan Vicens en 1925, a quien conoció en la Residencia de Estudiantes. Aunque su carrera no se vio afectada tras casarse, debido a la voluntad de María Luisa de seguir trabajando asalariadamente, en varios momentos de su vida hay claros indicios de que en esta mujer instruida seguían arraigados los modelos de género predominantes ${ }^{47}$ :

\footnotetext{
${ }^{46}$ El Sol, 8 de junio de 1933, p. 2; JAE, "Expediente de Moliner Ruíz, Matilde", Expediente JAE/100-653.

${ }^{47}$ El matrimonio, que recibió post-mortem en 1999 un homenaje en la Residencia de Estudiantes (aunque todo el protagonismo fue para Juan Vicens) no perjudicó la trayectoria profesional de María Luisa, siquiera durante los años en los que se trasladó a París junto a su marido, que había creado la Librairie Espagnole junto a León Sánchez Cuesta. Juan VICENS, "Carta de Juan Vicéns de la Llave y
} 
En primer lugar, cuando María Luisa y Juan decidieron contraer matrimonio por la Iglesia por la presión de sus familias, pese a las dudas de la primera ante el matrimonio. Incluso, como afirmó en una entrevista posteriormente, nunca había deseado casarse, ni con Juan Vicens ni con cualquier otro hombre, por lo que lo que convenció a la biografiada a pasar por el altar, junto a las presiones familiares, fue que

"Este muchacho tenía medios para vivir, y los otros en aquella época no se sabía. Te casabas con una incógnita [...]. Yo era bibliotecaria, pero ya me planteaba la cuestión, si me casaba, de trabajar o no trabajar. [Mi marido] quería que no trabajara. No te creas que yo me casé muy enamorada [...]. Todo el mundo decía [que tenía suerte]. Y yo decía ¿Por qué?"48.

En segundo lugar, esta tendencia también se aprecia cuando, durante la luna de miel del matrimonio, enviaban cartas a Federico García Lorca. En todos los escritos se aprecia cómo es Juan Vicens el que ocupaba la mayoría del espacio disponible, pese a que la amistad de María Luisa con García Lorca era más longeva e igual de profunda. De hecho, la historiadora sólo dispone en estas cartas y postales de un pequeño espacio, situando su rúbrica siempre debajo de la de su marido ${ }^{49}$. En tercer lugar, también queda patente cuando tras la guerra civil el matrimonio tomó caminos separados, ya que María Luisa asumió completamente el cargo de sus hijos, a pesar de que intentó liberarse en la URSS de las tareas de cuidados:

"Pensaba dejarles en un sanatorio y venirme yo otra vez a Madrid. Yo quería quitarme un poco el peso de los hijos, porque yo tenía también que vivir mi vida [pero finalmente me quedé en la URSS junto a ellos]"

Por último, volvió a apreciarse posteriormente cuando María Luisa realizó un nuevo sacrificio por su marido. Tras reencontrarse en la URSS con Juan Vicens después de muchos años, el matrimonio salió hacia la China Popular a mediados de

María Luisa González a Federico García Lorca”, Ávila, 15 de octubre de 1925, COA-1024. Archivo Fundación Federico García Lorca (AFFGL); Ramón SALABERRÍA LIZARAZU, "Las bibliotecas populares...", op. cit., pp. 309-310.

${ }^{48}$ Entrevista oral a María Luisa González. Proyecto de investigación fuentes orales de la Residencia de Estudiantes (1990). ARE.

49 Juan VICENS, "Tarjeta postal de Juan Vicéns de la Llave y María Luisa González a Federico García Lorca", Mallorca, 29 de octubre de 1925, COA-1025. AFFGL; Juan VICENS y María Luisa GONZÁLEZ, "Carta de Juan Vicéns de la Llave y María Luisa González a Federico García Lorca", Mallorca, 14 de noviembre de 1925, COA-1026. AFFGL.

${ }^{50}$ Entrevista oral a María Luisa González. Proyecto de investigación fuentes orales de la Residencia de Estudiantes (1990). ARE. 
los años cincuenta con el objetivo de colaborar en el montaje y funcionamiento de las emisoras de Radio Pekín para España y América Latina, así como de asesorar en la puesta en marcha de proyectos editoriales y en la enseñanza del español en instituciones pedagógicas. Si bien es cierto que, como mostré, China le ofreció nuevos e interesantes retos profesionales, María Luisa había dejado su trabajo como profesora universitaria por seguir a su marido al país asiático ${ }^{51}$.

\subsection{Los obstáculos adicionales que sufrieron por ser mujeres}

Las cuatro biografiadas sufrieron en su trayectoria profesional y académica la discriminación y los obstáculos adicionales por el hecho de ser mujeres, de una manera similar a cómo los padecieron el resto de universitarias en España durante estas décadas. Como las trabas extra fueron múltiples y variadas, a continuación voy a mostrar tres ejemplos que son representativos de las discriminaciones más habituales.

En primer lugar, al finalizar la enseñanza secundaria María Luisa pidió que se le permitiese opositar a las becas anunciadas por la Junta de los Colegios Universitarios de Salamanca, ya que existían precedentes de mujeres que habían sido exoneradas del requisito de ser varón para poder concurrir a la convocatoria. Como la institución se negó el Ministerio de Instrucción Pública y Bellas Artes intervino para autorizarla a opositar a dichas becas. Además, en la resolución del Ministerio se indicó que esa convocatoria no cumplía la legislación general establecida y que debía reformarse el Reglamento de los Colegios Universitarios de Salamanca, poniendo de acuerdo sus disposiciones con la Real Orden de 2 de septiembre de $1910^{52}$. En consecuencia, finalmente no sólo consiguió esta beca, sino que provocó una reforma encaminada a evitar que en el futuro la discriminación perviviese de forma institucionalizada y oficial. Sin embargo, no finalizaron ahí sus problemas porque, tal y como recuerda uno de sus hijos: "En los primeros días que acudía a clase se reunían en la escalinata hileras de machos para silbarle y decirle groserías" ${ }^{53}$. Este testimonio es muy interesante, porque muestra que el Estado y la legislación no son siempre los opresores; la presión de los

\footnotetext{
${ }^{51}$ Ramón SALABERRÍA LIZARAZU, "La larga marcha de Juan Vicens (Zaragoza, 1895-Pekín, 1958)", Educación y biblioteca, 108 (2000), p. 16; Blanca CALVO y Ramón SALABERRÍA, "Juan Vicens, inspector de Bibliotecas...", op. cit., p. 134.

${ }^{52}$ Gaceta de Madrid, 27 de septiembre de 1917, p. 799; La acción, 27 de noviembre de 1917, p. 2.

${ }^{53}$ Ramón SALABERRÍA LIZARAZU, “La larga marcha de Juan Vicens...”, op. cit., pp. 6-7.
} 
coetáneos ( $y$ de los pares, en este caso concreto) es muy eficaz. Hay que ser valiente para enfrentarse a eso y es lógico que muchas mujeres prefiriesen no exponerse a ese tipo de experiencias, "decidiendo libremente" no acudir a la universidad. Resaltar las situaciones de acoso por parte de los pares es fundamental, porque es algo menos abordado normalmente en las biografías de mujeres investigadoras.

El segundo ejemplo seleccionado es de finales de la dictadura de Primo de Rivera, en un contexto de lucha estudiantil frente al régimen debido a la clausura de universidades, pérdida de matrículas, etc. Como por su esencia paternalista el gobierno decidió no hacer extensivas estas medidas a las alumnas (lo cual es un hecho no igualitario que no debe considerarse como discriminación positiva), un grupo de mujeres universitarias de la Universidad de Madrid, entre las que se encontraba Amada López, Encarnación Fuyola, María Teresa Toral o Encarnación Corrales (hermana de la biografiada Pilar Corrales), dirigió al ministro de Instrucción pública un documento fechado a 25 de abril de 1929 en el que afirmaron que:

"Consideramos que la galantería en este caso es incompatible con nuestro sentimiento de la justicia. No acudiremos a la convocatoria de exámenes del próximo mes de septiembre, porque deseamos permanecer solidarizadas con la causa de la Universidad, que es la de la cultura española, lo mismo que nuestros compañeros estudiantes, con quienes nos sentimos plenamente identificadas en la defensa que han hecho de los derechos del Estado en materia de enseñanza. Nosotras en la Universidad somos y seguiremos siendo [...] compañeras leales de nuestros leales amigos, sobre todo en estos momentos de dura persecución contra ellos" ${ }^{\text {54. }}$.

El último ejemplo seleccionado tuvo lugar en los años setenta. Poco antes de jubilarse, Matilde Moliner apoyó la demanda de sus compañeras profesoras más jóvenes para que los conserjes del Instituto Cervantes al avisar del fin de la clase, especificaran, según el caso, "la hora, señora profesora" o "la hora, señor profesor", ya que hasta entonces siempre usaban la segunda fórmula. Este caso sirve para ilustrar como las discriminaciones informales y del lenguaje pervivieron durante todo el siglo XX (continúan todavía), al igual que la identificación de lo masculino con lo universal ${ }^{55}$.

\footnotetext{
${ }^{54}$ El Sol, 18 de mayo de 1930, p. 10. Fue la primera vez en la que el documento salió a la luz.

${ }^{55}$ Josefa OTERO, “Matilde Moliner...", op. cit., pp. 115-126.
} 


\section{Conclusiones}

El método prosopográfico ha permitido iniciar la construcción de una genealogía de historiadoras que supone no sólo hacerlas visibles, sino valorar, con las herramientas que aporta la perspectiva de género, las carreras profesionales, las dificultades y barreras a las que tuvieron que enfrentarse, las estrategias que utilizaron para rebelarse respecto al modelo de mujer socialmente aceptable, etc. Aunque no he olvidado que sus aspiraciones eran formar parte de un ámbito académico eminentemente masculino que, en su evolución durante el primer tercio del siglo XX, dejó abiertos algunos resquicios legales para las mujeres universitarias (en parte gracias a las ideas de la ILE) que se cerraban cuando las aspiraciones de las estudiantes superaban las de licenciarse. En consecuencia, las normas implícitas de la profesión y el modelo de mujer socialmente aceptado redujeron las alternativas laborales de estas historiadoras al CFABA y a la segunda enseñanza.

Las cuatro investigadoras de la prosopografía fueron mujeres pioneras que tensaron los límites de la respetabilidad de género, pero manteniéndose dentro de los modelos de género hegemónicos de las décadas en las que vivieron. Es decir, las prácticas que desarrollaron estas licenciadas negociaron o exploraron los límites borrosos de los modelos normativos, pero no llegaron a ser rupturistas con los mismos. $\mathrm{Si}$ bien realizaron algunas cosas que hubiesen sido inaceptables socialmente para muchas españolas de su época, porque suponían desafiar lo que se esperaba de ellas como mujeres, las cuatro historiadoras supieron negociar con éxito los márgenes de la respetabilidad de género al aprovecharse de su clase social, del prestigio que les otorgaba el alto nivel cultural que ostentaban, de la narrativa de la regeneración en España, de la incipiente feminización de las humanidades, etc. En consecuencia, estas españolas pudieron permitirse el aventurarse a realizar estancias investigadoras en el extranjero, el intentar conseguir el título de doctoras o el continuar trabajando asalariadamente después de contraer el matrimonio y tener hijos (aunque de las mujeres en general se esperaba más la maternidad, de quienes quisiesen hacer carrera profesional o académica se esperaba la soltería). Incluso, aunque ninguna estuvo vinculada a organizaciones feministas, pudieron permitirse en momentos puntuales reivindicar diversos cambios encaminados a beneficiar a las mujeres. 
Asimismo, tuvieron muchas actuaciones en su vida que cuadraban de forma ajustada con las prácticas de género socialmente aceptadas para las mujeres. Por un lado, se dedicaron profesionalmente a actividades que se asemejaban simbólicamente a otras significadas tradicionalmente como femeninas, como los cuidados o la enseñanza, por lo que eran consideradas como profesiones adecuadas para las mujeres; es más, cada vez en mayor medida estaban desempeñándose por españolas. Por otro lado, parece que cuando tuvieron hijos se hicieron completamente cargo de ellos, ya que no hay indicios que dispusieran de niñeras. $\mathrm{Y}$, por último, estas historiadoras (aquellas de las que he obtenido información suficiente sobre su vida privada como para analizar si reprodujeron en la vida cotidiana, o no, los discursos de género hegemónicos de cada momento) se plegaron de una forma u otra en su vida privada a concepciones más convencionales de "mujer".

También esta prosopografía ha servido para mostrar cómo incluso aquellas mujeres privilegiadas que pudieron acceder a estudios universitarios y dedicarse a una profesión de forma remunerada y de manera oficial (buena parte del trabajo femenino estaba oculto de los registros por diversos motivos), tuvieron que enfrentarse durante su trayectoria profesional y académica a muchos obstáculos extra respecto a los varones por el hecho de ser mujeres.

Por último, me gustaría resaltar que para que estas conclusiones provisionales y parciales puedan ser más sólidas, sería necesario realizar en el futuro más estudios sobre mujeres investigadoras en humanidades y en ciencias sociales nacidas a finales del siglo XIX y a comienzos del XX. Además, esto serviría para poder comparar con un mayor número de casos las trayectorias de estas mujeres de la primera generación de investigadoras respecto a las de las investigadoras de las generaciones posteriores, especialmente con aquellas españolas nacidas tras la guerra, ya que la dictadura cercenó el proceso de modernización y abrió un nuevo escenario para las mujeres que las relegó en el mundo académico prácticamente a la posición de partida, iniciada precisamente por estas historiadoras en la década de los años veinte. 